\title{
Coronary flow reserve and diastolic dysfunction in hypertrophic cardiomyopathy
}

\author{
Folkert J. Ten Cate, Patrick W. Serruys \\ Thoraxcenter, Erasmus University, Rotterdam, The Netherlands \\ (Received 21 January 1987; revision accepted 28 April 1987)
}

Ten Cate FJ, Serruys PW. Coronary flow reserve and diastolic dysfunction in hypertrophic cardiomyopathy. Int J Cardiol 1987;17:25-36.

We studied 14 patients with hypertrophic cardiomyopathy during and after atrial pacing by simultaneous registration of left ventricular high fidelity pressure measurements and M-mode echocardiography together with great cardiac vein flow measured by thermodilution. Heart rate rose from $75 \pm 18$ to $142 \pm 14$ beats/minute with an increase of $93 \pm 30$ to $127 \pm 46$ milliliters/minute of great cardiac vein flow (increase of flow / beat: 0.8 versus 1.5 milliliters / beat in normal individuals; $P<0.05$ ).

In addition, diastolic hemodynamic parameters (such as left ventricular end-diastolic pressure, $T_{1}$ (time constant of relaxation) (of first 40 milliseconds) and $T_{2}$ (of second 40 milliseconds) and $L V d P / d t$-) changed from, respectively, 27.4 \pm 7.1 to $24.0 \pm 10.3 \mathrm{~mm} \mathrm{Hg}$; (NS), $67.3 \pm 16.1$ to $65.7 \pm 22.2$ liters / second; (NS) $68.6 \pm 36.9$ to $52.9 \pm 19.4(P<0.05)$, and $1592 \pm 75$ to $1302 \pm 48 \mathrm{~mm} \mathrm{Hg} / \mathrm{sec} ; P<0.05$.

Left ventricular end-diastolic dimensions decreased whereas end-diastolic wall thickness increased from, respectively, $37 \pm 3$ to $34 \pm 4$ millimeters; $(P<0.05)$ and $14 \pm 2$ to $17 \pm 1$ millimeters $(P<0.05)$. Eleven of the 14 patients experienced angina pectoris concomitant with ST-T depression of 1 millimeter or more on the electrocardiogram.

No correlations were found between great cardiac venous flow and hemodynamically or ultrasonically derived diastolic parameters of left ventricular function.

Key words: Coronary vascular reserve; Diastolic dysfunction; Hypertrophic cardiomyopathy

Correspondence to: Folkert J. ten Cate, Department of Experimental Cardiology, Erasmus University, P.O. Box 1738, 3000 DR Rotterdam, The Netherlands. 


\section{Introduction}

A decrease in coronary reserve (as demonstrated by a reduction in the capacity of myocardial flow to increase after atrial pacing) has been proposed as a potential mechanism for ischemia in hypertrophic cardiomyopathy [1]. Although several mechanisms to explain ischemia have been suggested, such as intramyocardial small vessel disease [2], septal perforator artery compression [3], coronary arterial spasm [4] and, most recently, a high left ventricular filling pressure [5], no study until now has addressed the relation of the diastolic properties of the left ventricle to the coronary reserve in hypertrophic cardiomyopathy. We undertook a study using simultaneous high fidelity pressure measurements and M-mode echocardiograms at rest and during atrial pacing to determine left ventricular relaxation and filling abnormalities in relation to great cardiac venous flow, measured by thermodilution. Thus, we have made an attempt to show whether the diastolic abnormalities and coronary flow are correlated.

\section{Methods}

\section{Patients}

Fourteen patients with hypertrophic cardiomyopathy were studied (seven male, seven female; ages, $47 \pm 18$ years) by M-mode echocardiography and right and left cardiac catheterization (Table 1). The diagnosis of hypertrophic cardiomyopathy was based on echocardiographic [6], angiocardiographic and hemodynamic criteria [7]. All patients had hypertrophied nondilated left ventricles, without any signs of acquired or congenital heart disease. All had abnormal cross-sectional echocardiograms showing severe left ventricular hypertrophy involving several segments of the left ventricular walls according to criteria as described by Maron and his colleagues [8].

Six patients had pressure gradients across the left ventricular outflow tract during left heart catheterization of $50 \mathrm{~mm} \mathrm{Hg}$ or more which increased in four patients. One patient had a small pressure gradient of $12 \mathrm{~mm} \mathrm{Hg}$ at rest which increased to $166 \mathrm{~mm} \mathrm{Hg}$ upon provocation by isoprenaline (1 microgram/milliliter). In six patients, an insignificant pressure gradient was present at rest or during provocation. Drug treatment was discontinued at least 48 hours before cardiac catheterization. All patients were functionally limited at the time of hemodynamic evaluation (validity II or III, according to criteria of the New York Heart Association (see Table 1). Selection of the patients for the present study was based on lack of improvement of symptoms despite medical treatment (beta-blockade or verapamil). Informed consent was obtained from all patients and the study protocol was approved by the Thoraxcenter Medical Ethical Committee.

No patient had significant coronary arterial disease on coronary arteriography. The findings out of the present study were compared to "normal" findings from 15 individuals out of our laboratory. 


\section{Cardiac Catheterization and Angiography}

The procedure for this evaluation for our patients has been described earlier [9].

Left Ventricular Pressure Analysis. Briefly, left ventricular pressure and its derivatives $(\operatorname{LVd} P / \mathrm{d} t+; \operatorname{LVd} P / \mathrm{d} t-$ and $V \max )$ were calculated on-line via an automated data processing system [9].

For off-line analysis of left ventricular pressure relaxation, an updated version of the beat to beat program described previously was used with the following definitions: (1) pressure at the beginning of isovolumic relaxation $\left(P_{\mathrm{b}}\right)$ is the pressure at the point at which $\mathrm{d} P / \mathrm{d} t$ is minimal (maximum negative $\mathrm{d} P / \mathrm{d} t$ ), and (2) pressure at the end of isovolumetric relaxation $\left(P_{\mathrm{e}}\right)$ is the pressure less than or equal to the previous end-diastolic pressure, but no less than $1 \mathrm{~mm} \mathrm{Hg}$. Although it is possible that the latter definition may result in $P_{\mathrm{e}}$ being measured just after mitral valve opening, estimation of the time constants by more stringent criteria, such as end-diastolic pressure $1 / 210 \mathrm{~mm} \mathrm{Hg}$, did not result in a significantly better estimation, and failed to measure pressure during high heart rates.

The technique implemented for the off-line beat to beat calculation of the relaxation parameters was the semilogarithmic model. A minimum of eight samples (over 32 milliseconds) was required between $P_{\mathrm{b}}$ and $P_{\mathrm{e}}$. No other computations were attempted.

The semilogarithmic model used was $P(t)=P_{0} e^{-t / T}$, where $P$ is pressure; $P_{0}$ is equivalent to $P_{\mathrm{b}}$ when a true exponential decay is present starting from the time of peak negative $\mathrm{d} P / \mathrm{d} t$. The $P_{0}$ and $T$ parameters were estimated from a linear least squares fit on $\ln P=-t / T+\ln P_{0}$. In addition, a biexponential fit for isovolumic relaxation was determined characterized by the two exponential time constants; the fit for the first 40 milliseconds, $T_{1}$, and the fit after the first 40 milliseconds, $T_{2}$.

\section{Coronary Flow Measurements}

Great cardiac venous flow was measured using a thermodilution Ganz catheter [10]. Coronary vascular resistance was derived from the ratio of mean aortic pressure to great cardiac vein flow. Atrial pacing was performed via a pacing catheter introduced separately into the right atrium and was performed at incremental steps of 10 beats/minute at 1-minute intervals until maximal heart rate was reached. Thereafter pacing was terminated immediately. If patients developed angina pectoris or conduction disturbances were seen pacing was also discontinued. During cardiac catheterization left ventricular pressures, aortic pressures and the electrocardiogram were registrated continuously at low and high speed. Left ventricular pressures and aortic pressures were determined simultaneously with the electrocardiogram and the M-mode echorecordings continuously at rest, during atrial pacing and after pacing was discontinued (see also Fig. 1). To exclude potential effects of angiographic dye on coronary flow, great cardiac venous flow was measured at least 20 minutes after the use of angiographic dye. 


\section{Echocardiography}

M-mode echocardiograms of the left ventricle were made in all patients at a paper speed of 50 millimeters/second. We used a 0.5 -inch diameter, 2.25-megahertz transducer focused at 7.5 centimeters. The M-mode echocardiograms were recorded in a standard fashion we described earlier [9].

Briefly, during examination with the patient in the supine or slightly lateral decubitus position, several M-mode sector scans were taken from the level of the aortic root across the left ventricular cavity to the left ventricular apex. The transducer was placed on the chest wall and was held perpendicularly when the largest amplitude of motion of the anterior mitral leaflet was recorded. The M-mode echocardiograms of the left ventricle were always obtained at a level just below the tips of both mitral leaflets, and gain settings were continuously adjusted to obtain optimal resolution of endocardial surfaces of both interventricular septum and left ventricular posterior wall. The left ventricular and aortic pressures were recorded simultaneously with the recording of $\mathrm{M}$-mode echocardiograms and electrocardiograms. To analyze the same beats for left ventricular pressures and echocardiograms, "precise" timing by zero-calibration markers of left ventricular pressures was used. From the echocardiograms left and right ventricular dimensions, interventricular septal thickness and posterior wall thickness at end-diastole and end-systole [11] were measured at rest, during atrial pacing and after pacing [12].

\section{Left Ventricular Weight}

Left ventricular weight was measured from the cineangiocardiograms in right anterior oblique position according to a method as described previously for our laboratory and expressed in grams/square meter [13].

Although this method is of limited value in this group of patients, we used this method to correct our measurements for left ventricular weight since the limitations of this method apply to all patients studied.

\section{Statistical Analysis}

The statistical significance of the data was assessed by Student's $t$-test. Values were expressed as mean \pm standard deviation. A value of less than 0.05 was considered to indicate significance.

\section{Results}

\section{Hemodynamic Findings}

In all patients atrial pacing was carried out and $\mathrm{M}$-mode echocardiograms and left ventricular pressures measured simultaneously (Fig. 1). In 12 patients great cardiac vein flow was available at rest whereas in 11 patients great cardiac vein flow at rest, at peak pacing rates and directly after pacing was obtained. In three patients 


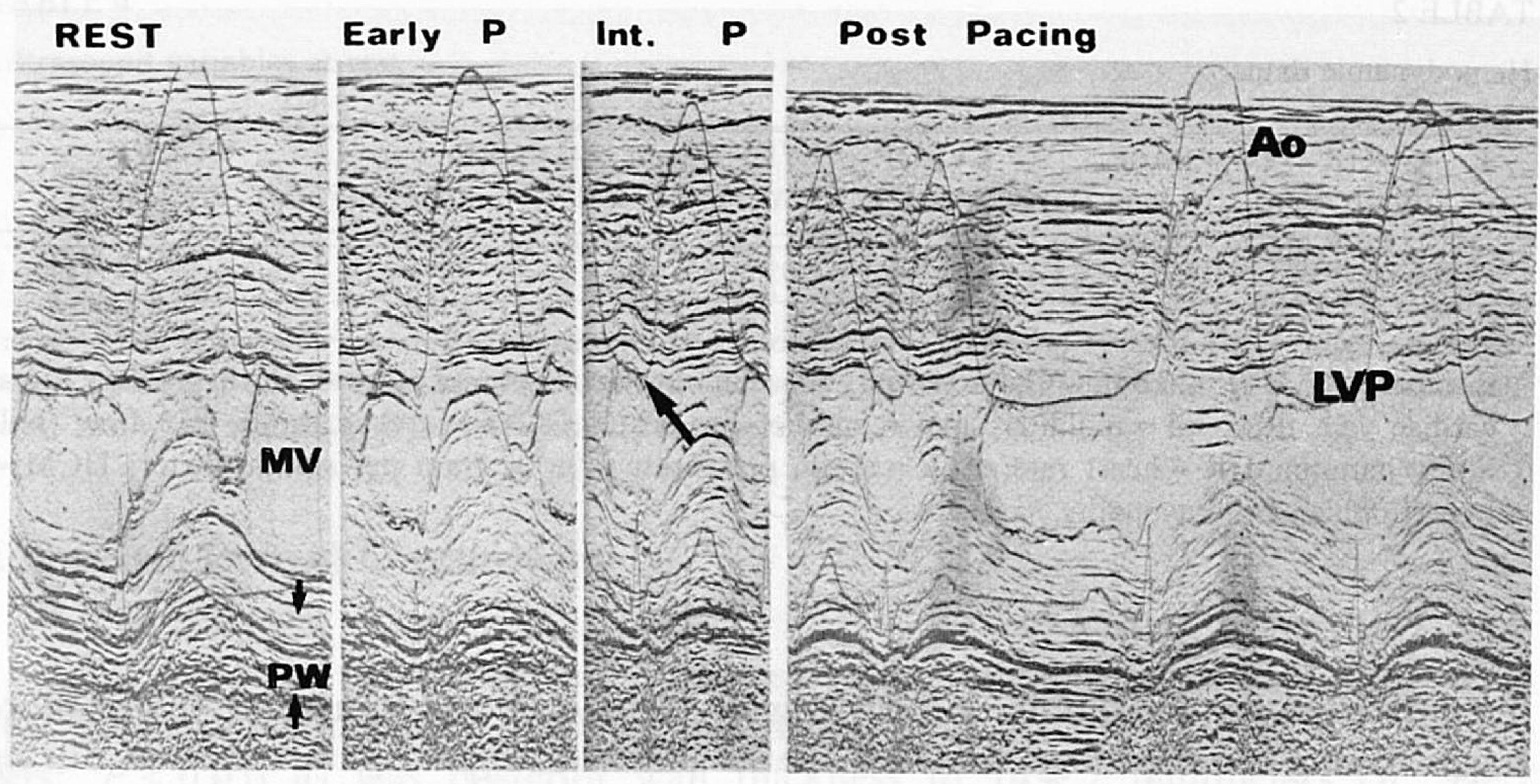

Fig. 1. Ultrasound hemodynamic registration during and after atrial pacing (Patient 13). Observe the abnormal response of the left ventricular pressure during diastole (large arrow) and the increase of posterior wall thickness during atrial pacing. $\mathrm{MV}=$ mitral valve; $\mathrm{PW}=$ left ventricular posterior wall; $\mathrm{P}=$ pacing; Int. $=$ intermediate; $A \mathrm{o}=$ aortic pressure; $\mathrm{LVP}=$ left ventricular pressure.

TABLE 1

Clinical data.

\begin{tabular}{|c|c|c|c|c|c|c|c|}
\hline Patient & Age & Sex & Validity & $\begin{array}{l}\text { LVOT } \\
\text { rest }\end{array}$ & $\begin{array}{l}\text { Gradient } \\
\text { provocation }\end{array}$ & $\begin{array}{l}\text { Mitral } \\
\text { incompetence }\end{array}$ & $\begin{array}{l}\text { Pain during } \\
\text { atrial pacing }\end{array}$ \\
\hline 1 & 20 & $\mathrm{~F}$ & III & 90 & Valsalva 100 & - & + \\
\hline 2 & 22 & M & II & - & $\mathrm{V} / \mathrm{I}$ & - & - \\
\hline 3 & 67 & $\mathrm{~F}$ & III & - & $\mathrm{V} / \mathrm{I}$ & - & + \\
\hline 4 & 48 & $\mathrm{~F}$ & III & - & $\mathrm{V} / \mathrm{I}$ & - & + \\
\hline 5 & 15 & M & II /III & 50 & I 100 & - & + \\
\hline 6 & 49 & M & II & 150 & $\begin{array}{l}\text { no provocation } \\
\text { during APST } 48\end{array}$ & gr I & + \\
\hline 7 & 58 & M & II & - & $\mathrm{V} / \mathrm{I}$ & - & + \\
\hline 8 & 66 & $\mathrm{~F}$ & III /IV & 120 & no provocation & gr I & + \\
\hline 9 & 54 & $\mathrm{~F}$ & II /III & 80 & $\mathrm{~V} / \mathrm{I}$ & gr I & - \\
\hline 10 & 59 & $\mathrm{~F}$ & III & - & $\mathrm{V} / \mathrm{I}$ & - & + \\
\hline 11 & 20 & $\mathrm{~F}$ & II /III & - & 50 & gr I & + \\
\hline 12 & 67 & $\mathrm{~F}$ & II & 10 & $\mathrm{~V} / \mathrm{I}$ & gr I & + \\
\hline 13 & 47 & M & II & 50 & $\mathrm{~V} / \mathrm{I}$ & gr II/III & + \\
\hline 14 & 54 & M & II /III & 12 & 166 & gr II & + \\
\hline $\bar{x} \pm \mathrm{SD}$ & $46.7 \pm 18$ & & & $52.2 \pm 31.4$ & & & \\
\hline
\end{tabular}

Validity according to New York Heart Association criteria. Gradients were determined at rest and after provocation with the (V) Valsalva maneuver and isoprenaline (1 microgram/milliliter) infusion (I). See also text and Table 2. Mitral incompetence visually graded (grade I to III). LVOT=left ventricular outflow tract. Gradients were expressed in $\mathrm{mm} \mathrm{Hg}$. For further explanations and abbreviations see text. 
TABLE 2

Hemodynamic data.

\begin{tabular}{lllllll}
\hline & $\begin{array}{l}\text { HR } \\
(\mathrm{b} / \mathrm{min})\end{array}$ & $\begin{array}{l}\text { AoP } \\
(\mathrm{mm} \mathrm{Hg})\end{array}$ & $\begin{array}{l}\text { LVEDP } \\
(\mathrm{mm} \mathrm{Hg})\end{array}$ & $\begin{array}{l}\text { LV weight } \\
\left(\mathrm{g} / \mathrm{m}^{2}\right)\end{array}$ & $\begin{array}{l}\text { CVR } \\
(\mathrm{mm} \mathrm{Hg} \cdot \mathrm{ml} / \mathrm{min})\end{array}$ & $\begin{array}{l}\text { GCVF } \\
(\mathrm{ml} / \mathrm{min})\end{array}$ \\
\hline HCM & $75.6 \pm 17.2$ & - & $23.1 \pm 6.8^{*}$ & $137.2 \pm 33.6^{*}$ & $0.6 \pm 0.2$ & $98.6 \pm 37.01$ \\
Normal & $75 \pm 6$ & - & $8.4 \pm 1.2$ & $96 \pm 16$ & $1.2 \pm 0.2^{*}$ & $68.4 \pm 20.3$ \\
\hline
\end{tabular}

* Compared to $N(P<0.05)$. CVR = coronary vascular resistance defined as mean aortic pressure/great cardiac vein flow; $\mathrm{ml}=$ milliliter; $\min =$ minute; $\mathrm{b}=$ beats; $\mathrm{GCVF}=$ great cardiac vein flow (milliliter $/$ minute); $\mathrm{HR}=$ heart rate; $\mathrm{AoP}=$ aortic pressures; $\mathrm{g} / \mathrm{m}^{2}=$ gram per square meter; $\mathrm{HCM}=$ hypertrophic cardiomyopathy.

the data from the thermodilution curve were technically inadequate at one or more stages during atrial pacing. In 11 of the 14 patients anginal pain occurred during atrial pacing (Table 1) together with ST-T depressions of 1 millimeter or more on the electrocardiogram. Table 2 shows the hemodynamic data for the patients with hypertrophic cardiomyopathy and the group of normal individuals. The results of the hemodynamic analysis before, during and after atrial pacing are shown in Table 3.

Left ventricular end-diastolic pressure decreased in seven patients whereas it increased in seven patients. However, after pacing, left ventricular end-diastolic pressure remained abnormally high in all $(29.1 \pm 7.1 \mathrm{~mm} \mathrm{Hg} ; P<0.05)$ (see Table 3).

In controls there was always a decrease in left ventricular end-diastolic pressure during atrial pacing (5) with an increase of $T_{1}$ and $T_{2}$.

TABLE 3

LV systolic and diastolic parameters during atrial pacing.

\begin{tabular}{lrrr}
\hline \multicolumn{1}{c}{1} & \multicolumn{1}{c}{2} \\
\hline HR & $75 \pm 434$ & $142 \pm 14^{*}$ & $76 \pm 17$ \\
LVd $P / \mathrm{d} t+$ & $1670 \pm 434$ & $2005 \pm 758^{*}$ & $1894 \pm 554^{* *}$ \\
LVd $P / \mathrm{d} t-$ & $1592 \pm 752$ & $1302 \pm 482^{*}$ & $1554 \pm 598$ \\
$T_{1}$ & $67 \pm 16$ & $65 \pm 22$ & $97 \pm 34^{* *}$ \\
$T_{2}$ & $68 \pm 13$ & $52 \pm 19 *$ & $74 \pm 21$ \\
LVESP & $80 \pm 11$ & $73 \pm 8 *$ & $79 \pm 10$ \\
LVEDP & $24 \pm 7$ & $24 \pm 10$ & $29 \pm 7$ \\
GCVF & $93 \pm 30$ & $127 \pm 46$ & $122 \pm 58$ \\
\hline
\end{tabular}

$\mathrm{HR}=$ heart rate (beats $/$ minute); $\mathrm{LVd} P / \mathrm{d} t=$ first derivative of $\mathrm{LV}$ pressure $(\mathrm{mm} \mathrm{Hg} / \mathrm{sec}) ; T=$ time constant of relaxation (liters/second); LVESP $=\mathrm{LV}$ end-systolic pressure $(\mathrm{mm} \mathrm{Hg}) ; \mathrm{LVEDP}=\mathrm{LV}$ end-diastolic pressure (millimeters of mercury); GCVF = great cardiac vein flow (milliliters/minute); $1=$ rest $; 2$ = peak pacing rate; $3=$ immediately after pacing. For further explanation, see text. All values expressed as $\bar{x} \pm \mathrm{SD} .{ }^{*} P<0.05$ between 1 and $2 ;{ }^{*}{ }^{*} P<0.05$ between 1 and 3 . 
TABLE 4

Ultrasound variables at rest.

\begin{tabular}{|c|c|c|c|c|c|c|c|}
\hline & \multicolumn{2}{|l|}{ LVID } & \multirow{2}{*}{$\begin{array}{l}\text { Ratio } \\
\text { IVS/LVPW }\end{array}$} & \multirow{2}{*}{$\begin{array}{l}\text { IVS } \\
(\mathrm{mm})\end{array}$} & \multirow{2}{*}{$\begin{array}{l}\text { LVPW } \\
(\mathrm{mm})\end{array}$} & \multirow{2}{*}{$\begin{array}{l}\text { Type LVH } \\
\text { (CSE) }\end{array}$} & \multirow{2}{*}{$\begin{array}{l}\text { LA } \\
(\mathrm{mm})\end{array}$} \\
\hline & $\overline{\mathrm{ED}}$ & ES & & & & & \\
\hline $\bar{x} \pm \mathrm{SD}$ & $37.8 \pm 4.2$ & $20.6 \pm 4.6$ & $1.5 \pm 0.1$ & $20.6 \pm 2.6$ & $13.9 \pm 1.8$ & II $/$ III & $42 \pm 2.7$ \\
\hline
\end{tabular}

LVID = left ventricular internal dimension; $\mathrm{ED}=$ end-diastole; $\mathrm{ES}=$ end-systole; IVS = interventricular septal thickness; CSE = cross-sectional echocardiography; LVPW $=$ left ventricular posterior wall thickness; $\mathrm{LA}=$ left atrium; $\mathrm{LVH}=$ left ventricular hypertrophy.

\section{Ultrasound Derived Measurements}

Table 4 showed the ultrasound variables at rest; interventricular septal thickness was substantially increased to $21 \pm 3$ millimeters at end-diastole ( $n: 10 \pm 2$ millimeters; $P<0.05)$ as was posterior wall thickness to $14 \pm 2$ millimeters $(n: 9 \pm 2$ millimeters; $P<0.05$ ). Two-dimensional analysis of left ventricular hypertrophy [8] showed type II or III hypertrophy in all patients, indicating that most segments of septal and anterolateral walls were hypertrophied. An abnormal systolic anterior motion of the mitral valve was present in nine patients.

Table 5 shows the ultrasound parameters before, during and after atrial pacing.

Pressure-Dimension Curves. Pressure-dimension curves shifted upward or to the left in seven patients (Fig. 2) but showed a different response in another seven, because left ventricular end-diastolic pressure decreased during pacing. Pressure wall thickness curves during diastole went to the right in all.

\section{Relation between Great Cardiac Vein Flow and Diastolic Hemodynamic and Ultra- sound Parameters}

No correlation was found between great cardiac venous flow and $T_{1}, T_{2}$ and wall thickness, respectively, either at rest or during or after atrial pacing.

TABLE 5

Ultrasound parameters during atrial pacing.

\begin{tabular}{llll}
\hline & 1 & 2 & 3 \\
\hline LVID (ED) & $37 \pm 4$ & $34 \pm 4^{*}$ & $40 \pm 2^{* *}$ \\
LVID (ES) & $21 \pm 3$ & $16 \pm 3^{*}$ & $22 \pm 2$ \\
LVPW (ED) & $14 \pm 2$ & $17 \pm 1^{*}$ & $16 \pm 2^{* *}$ \\
LVPW (ES) & $21 \pm 3$ & $22 \pm 5$ & $22 \pm 2$ \\
\hline
\end{tabular}

Abbreviations as before. ${ }^{*} P<0.05$ as compared 1 versus 2 ; ${ }^{*} * P<0.05$ as compared 1 versus 3 . For explanation, see text. Values expressed as $\bar{x} \pm \mathrm{SD}$. 


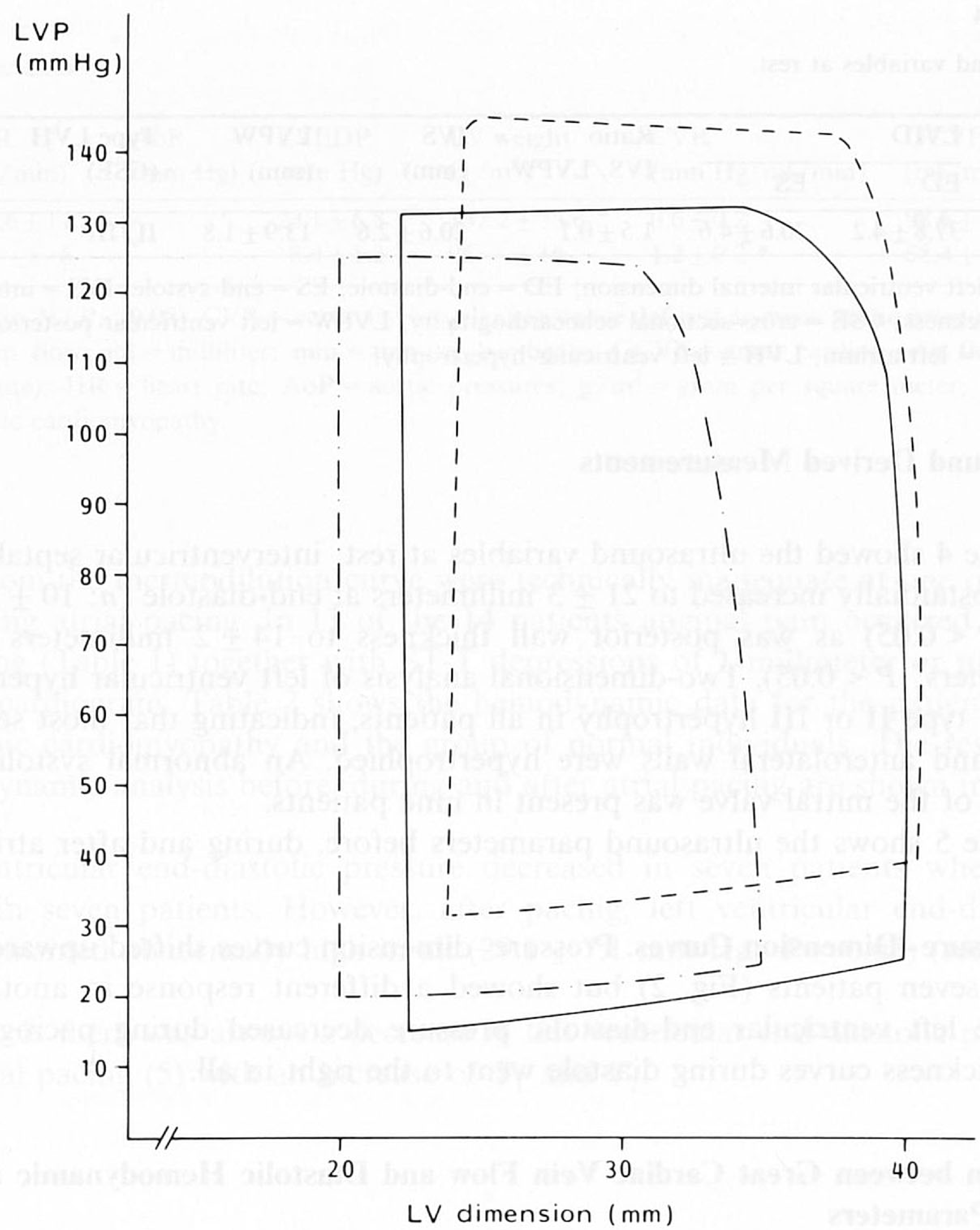

Fig. 2. Pressure-dimension curve (Patient 6), at rest, at peak pacing rates and directly after pacing. Observe a shift of the pressure-dimension curve upwards and to the left indicating decreased compliance of the left ventricle, during atrial pacing.

Great cardiac vein flow $=19.6+0.1 T_{1}, r=0.10, P=$ not significant $; 20.5+10$ $T_{2}, r=0.21, P=$ not significant; $-2.8+3.7 \log$ wall thickness, $r=0.20, P=$ not significant.

Also the relative increase or decrease of GCV flow ( $\Delta \mathrm{GCVF}$ ) and $T_{1}\left(\Delta T_{1}\right)$, $T_{2}\left(\Delta T_{2}\right)$ and wall thickness $(\Delta \mathrm{WT})$ did not show any correlation.

Great cardiac venous flow $=0.22+0.02$ wall thickness, $r=0.11, P=$ not significant; $19.4+1.0 T_{1}, r=0.10, P=$ not significant; $15.4+2.3 T_{2}, r=0.14, P=$ not significant.

Furthermore, no correlations were found between $T_{1}$ and wall thickness, either at rest or during atrial pacing. Wall thickness $=17.4+4.7 T_{1}, \quad r=0.31, P=$ not significant; $1.5-0.01 T_{2}, r=0.1, P=$ not significant. These results show that no 
direct correlation could be found between the diastolic parameters studied and coronary vascular reserve.

Variability of M-Mode Echomeasurements. These have been described before using the same hemodynamic ultrasonic technique in the same type of patients [9].

\section{Discussion}

In this limited group of patients with hypertrophic cardiomyopathy, no correlation was found between great cardiac venous flow and any parameter of left ventricular diastolic function (hemodynamically or echocardiographically measured) during atrial pacing.

Relaxation and filling abnormalities [14-16] are known to be present in hypertrophic cardiomyopathy. Clinical studies using echocardiography [17] and/or videodensitometry [18] have indicated that such patients with angina pectoris showed decreased diastolic wall thinning rates as compared to patients with complaints of either dyspnea or syncope, suggesting that angina pectoris is correlated with diastolic wall motion abnormalities. Although complaints of chest pain could sometimes be very atypical for angina pectoris, several authors [1-5] have emphasized that real angina pectoris due to ischemia might occur in hypertrophic cardiomyopathy. No definite studies have occurred as yet as far as known about mechanisms for ischemia in this setting such as vascular spasm, metabolic regulation of coronary flow or disturbed capacitance of intramural coronary vessels. Ischemia can be attributed to a decreased coronary vascular reserve [1] or an increased left ventricular end-diastolic pressure at higher heart rates [5] or both. Nevertheless, to the best of our knowledge, no study is available until now which has related the diastolic properties of the myocardium to hemodynamics and great cardiac venous flow simultaneously. Therefore we have postulated that, if ischemia due to a decreased coronary flow explains the relaxation abnormalities in these patients, a significant correlation between great cardiac venous flow and $T_{1}, T_{2}$ or wall thickness during atrial pacing must be present. But this correlation was not found. It is evident that our patients represent a selected group with extensive myocardial involvement by the myopathic process, the left ventricular end-diastolic pressures were high at rest and, from the cross-sectional echocardiographic analysis, the degree of myocardial hypertrophy was extensive. Recent observations using crosssectional echocardiography have shown that the degree of left ventricular myocardial hypertrophy was correlated with the extent of diastolic abnormalities [19].

It is well known from animal experiments that a certain perfusion pressure is needed to maintain an adequate coronary flow (so called "closing pressure"). If this critical closing pressure is reached, coronary vessels collapse and coronary flow ceases [20]. This phenomenon could have been present in our patients during tachycardia since perfusion pressure was decreased (aortic end-systolic pressure minus left ventricular end-diastolic pressure) and the myocardial extravascular forces (wall thickness) were increased. Both phenomena could have interfered with the inadequate increase of coronary flow during tachycardia. A decreased capillary 
density per unit mass has been proposed as the mechanism to explain the inadequate coronary vascular reserve in patients with left ventricular hypertrophy due to aortic stenosis or systemic hypertension. This mechanism was not studied in our patients with hypertrophic cardiomyopathy.

During atrial pacing tachycardia, left ventricular end-diastolic pressures and left ventricular diastolic dimensions should decrease [12,21] whereas wall thickness should increase. But the results of the present study show the opposite. Left ventricular end-diastolic pressures remained high whereas left ventricular dimensions decreased. This indicates a reduced compliance of the left ventricle with a shift of the pressure-dimension curve upwards and/or to the left (Fig. 2). Furthermore, end-diastolic wall thickness increased significantly. Thus, it can be argued that alterations of diastolic properties of the myocardium during tachycardia could attribute to an increased resistance to left ventricular filling with secondary changes in left ventricular systolic pressures.

It has recently been shown that atrial pacing induced ischemia in coronary arterial disease was always associated with a decreased compliance, although great cardiac venous flow in that particular study was not measured [22].

Although great cardiac venous flow measurements have limitations, to our opinion, and that of others [5], it is the best means presently available to determine coronary flow during cardiac catheterization.

The echo method has its own limitations, especially since simultaneous measurements with left ventricular pressures are used [9,11]. These have been discussed earlier for this combined hemodynamic-ultrasonic technique in hypertrophic cardiomyopathy. Earlier good inter- and intraobserver correlations [9] were present for the echo variables measured. Thus, although the methods we used have their own limitations, we believe that we have chosen the most optimal methodology currently available to study the relationship between the mechanical, hemodynamic and coronary flow events in patients with hypertrophic cardiomyopathy.

Recently Jasky [23] has found that, during occlusion and early ischemia, peak negative $\mathrm{d} P / \mathrm{d} t$ and time constant of relaxation increased with early diastolic shortening during isovolumic relaxation in patients who underwent angioplasty.

Although a decreased coronary flow reserve is present in hypertrophic cardiomyopathy and diastolic left ventricular function is impaired, the present study shows that the two phenomena are probably not directly related. Experimental studies from our institution and others [24,25] have shown that the changes in hemodynamic parameters and wall thickness can be also present when intracellular calcium cannot be used by the myocardium, for example, in the presence of calcium-channel blockers. In these studies epicardial coronary flow was not impaired. Nevertheless, myocardial function was severely depressed ("cardioplegic"). Therefore, we postulate that our findings can be explained by a disturbance in calcium metabolism. Clinical circumstantial evidence for this postulate is already present since it is known that calcium-channel blocking agents might improve diastolic filling [26]. 


\section{Acknowledgements}

We acknowledge the technical assistance of Willem B. Vletter and Inge Zorn, the statistical advice of Harald J. ten Katen, and the invaluable secretarial help of Henny Vegter.

\section{References}

1 Pasternac A, Noble J, Streulens Y, Elie R, Henscke C, Bourassa M. Pathophysiology of chest pain in patients with cardiomyopathy and normal coronary arteries. Circulation 1982;4:778-789.

2 Maron BJ, Epstein SE, Roberts WC. Hypertrophic cardiomyopathy and transmural myocardial infarction without significant atherosclerosis of the extramural coronary arteries. Am J Cardiol 1979;43:1086-1103.

3 Pichard AD, Meller J, Teichholz LE, Lipnick S, Gorlin H, Herman MV. Septal perforator compression (narrowing) in idiopathic hypertrophic subaortic stenosis. Am J Cardiol 1977;40:310-318.

4 Nishimura K, Nosaka H, Saito T, Nobayoski M. Another possible mechanism of angina in hypertrophic cardiomyopathy (abstract). Circulation 1983;68(suppl III):III-162.

5 Canon RO III, Rosing DR, Maron BJ, et al. Myocardial ischemia in patients with hypertrophic cardiomyopathy: contribution of inadequate vasodilator reserve and elevated left ventricular enddiastolic pressures. Circulation 1985;71:234-243.

6 Maron BJ, Epstein SE. Hypertrophic cardiomyopathy: recent observations regarding the specificity of three hallmarks of the disease: assymmetric septal hypertrophy, septal disorganization and systolic anterior motion of the anterior mitral leaflet. Am J Cardiol 1980;45:141-154.

7 Braunwald E, Morrow AG, Cornell WP, Aygen MM, Hilbish TF. Idiopathic hypertrophic subaortic stenosis: hemodynamic and angiographic manifestations. Am J Med 1960;29:924-945.

8 Maron BJ, Gottdiener JS, Epstein SE. Patterns and significance of distribution of left ventricular hypertrophy in hypertrophic cardiomyopathy. A wide-angle, two-dimensional echocardiographic study in 125 patients. Am J Cardiol 1981;48:418-428.

9 Ten Cate FJ, Serruys PW, Mey S, Roelandt J. Effects of shortterm administration of verapamil on left ventricular relaxation and filling dynamics measured by a combined hemodynamic-ultrasonic technique in patients with hypertrophic cardiomyopathy. Circulation 1983;68:1274-1279.

10 Ganz W, Tanura K, Marcus HS, Donoso R, Yoshida S, Swan HJC. Measurement of coronary sinus blood flow by continuous thermodilution in man. Circulation 1971;44:181-187.

11 O'Rourke RA, Hanrath P, Henry WL, et al. Report of the joint international society and federation of cardiology world health organization task force on recommendations for standardisation of measurements from M-mode echocardiograms. Circulation 1984;69:854A-857A.

12 Piérard LA, Meltzer RS, Vletter W, Serruys PW, Roelandt J. Comparison of digitized M-mode echocardiogram during supine exercise and atrial pacing at similar heart rates (abstract). Am J Cardiol 1982;49:905 (abstr).

13 Brower RW, Meester GT. Quantification of left ventricular function in patients with coronary artery disease In: Hwang NHC, ed. Quantitative cardiovascular studies. Baltimore: University Park Press, 1979;639-688.

14 Sanderson JE, Gibson DG, Brown DJ, Goodwin JF. Left ventricular filling in hypertrophic cardiomyopathy: an angiographic study. Br Heart J 1977;39:661-667.

15 St John Sutton MG, Tajke AJ, Gibson DG, Brown DJ, Seward JB, Giuliani ER. Echocardiographic assessment of left ventricular filling and septal and posterior wall dynamics in idiopathic hypertrophic subaortic stenosis. Circulation 1978;57:512-519.

16 Murgo JP, Craig WE. Relaxation abnormalities in hypertrophic cardiomyopathy. Circulation 1980;62(suppl III):316 (abstr.)

17 Ten Cate FJ, Balakumaran K, Mc Ghie J, Serruys PW, Roelandt J. Angina pectoris in hypertrophic cardiomyopathy (HCM): cause or consequence of disturbed relaxation? (abstract). Circulation 1980; 62 (suppl III): 317. (abstr). 
18 St John Sutton MG, Tajik AJ, Smith HC, Ritman EL. Angina in idiopathic hypertrophic subaorctic stenosis - a clinical correlate of regional left ventricular dysfunction: a videometric and echocardiographic study. Circulation 1980;61:561-567.

19 Spirito P, Maron BJ, Chiarella F, Bellotti P, Tramazin R, Pozzoli M, Vecchio C. Diastolic abnormalities in patients with hypertrophic cardiomyopathy: relation to magnitude of left ventricular hypertrophy. Circulation 1985;72:310-315.

20 Perautt S, Riley RL. Hemodynamics of collapsible vessels with tone: the vascular waterfall. J Appl Physiol 1963;18:924-940.

21 Brower RW, Remme WJ, Ten Katen HJ, Van der Brand MB. Quantification of the atrial pacing stress test: normal values and limits between normal and abnormal for coronary artery disease in man. Comp Cardiol 1977;4:591-603.

22 Aroesty JA, McKay RG, Heller GV, Royal HD, Als AV, Grossman W. Simultaneous assessment of left ventricular systolic and diastolic dysfunction during pacing-induced ischemia. Circulation 1985;71:889-900.

23 Jaski BE, Serruys PW. Epicardial wall motion and left ventricular function during coronary graft angioplasty in humans. J Am Coll Cardiol 1985;6:695-700.

24 Verdouw PD, Ten Cate FJ, Hugenholtz PG. Effect of nifedipine on segmental myocardial function in the anesthetized pig. Eur J Pharmacol 1980;63:209-212.

25 Clark RE, Christlieb IY, Henry PD. Nifedipine: A myocardial protective agent. Am J Cardiol 1979;44:825-831.

26 Rosing DR, Idapaam-Heikhila U, Maron BJ. Use of calciumchannel blocking drugs in hypertrophic cardiomyopathy. Am J Cardiol 1985;55:185B-195B. 